\title{
The Future of Induced Pluripotent Stem Cells for Cardiac Therapy and Drug Development
}

\author{
Lieven Thorrez* and Maurilio Sampaolesi
}

\author{
Translational Cardiomyology, Stem Cell Institute Leuven, Katholieke Universiteit Leuven, Herestraat 49, PB814 3000 Leuven, \\ Belgium
}

\begin{abstract}
The field of stem cell research was revolutionized with the advent of induced pluripotent stem cells. By reprogramming somatic cells to pluripotent stem cells, most ethical concerns associated with the use of embryonic stem cells are overcome, such that many hopes from the stem cell field now seem a step closer to reality. Several methods and cell sources have been described to create induced pluripotent stem cells and we discuss their characteristics in terms of feasibility and efficiency. From these cells, cardiac progenitors and cardiomyocytes can be derived by several protocols and most recent advances as well as remaining limitations are being discussed. However, in the short time period this technology has been around, evidence emerges that induced pluripotent stem cells may be more prone to genetic defects and maintain an epigenetic memory and thus may not be entirely the same as embryonic stem cells. Despite the lack of a complete fundamental understanding of stem cell biology, and even more of ways how to coax them into defined cell types, the technology is quickly adopted by industry. This paper gives an overview of the current applications of induced pluripotent stem cells in cardiovascular drug development and highlights active areas of research towards functional repair of the damaged heart. Adult stem cells have already been taken to clinical trials and we discuss these results in light of potential and hurdles to be taken to move induced pluripotent stem cells to the clinic.
\end{abstract}

Keywords: Cardiomyocyte, stem cells, drug discovery.

\section{INTRODUCTION: WHAT ARE PLURIPOTENT STEM CELLS?}

Already in 1958 it was shown that the genetic material of differentiated somatic cells could be reprogrammed by placing the nucleus of a somatic Xenopus cell into an enucleated oocyte, which generated a cloned Xenopus [1]. The first proof that nuclear transfer could reprogram adult mammalian cells came in 1997 with the cloning of the sheep Dolly [2]. A second technique, somatic cell fusion with an embryonic stem cell (ESC), showed that the somatic genome could be reprogrammed to an embryonic state [3]. These and other experiments demonstrated that the cytoplasm of oocytes or ESCs contains factors that can induce pluripotency in a somatic cell nucleus.

In 2006, Takahashi and Yamanaka were the first to show that somatic cells could be induced to ESC-like pluripotent cells by the expression of 4 transcription factors [4]. Based on their role in maintenance of ESC identity, 24 candidate genes were selected for retroviral transduction in mouse fibroblasts. Induction of pluripotency was assayed by activation of a selection marker placed after an ES-cell specific promoter. Transduction of all factors generated ESC-like cells, termed induced pluripotent stem cells (iPSC). By a series of experiments in which individual factors were withdrawn from the pool, 4 factors were found necessary for iPSC generation: OCT4 (official gene symbol POU5F1), SOX2, KLF4 and MYC. These iPSCs had growth properties, morphology and gene expression characteristics similar to ESCs. A year later, the same factors were also shown to be effective in human fibroblasts [5]. Independently, the group of James Thomson developed the method based on lentiviral transfer of a partially different set of 4 factors: OCT4, SOX2, NANOG and LIN28 [6]. KLF4 and MYC were not present in the pool of 14 factors that were initially used by Thomson and LIN28 was not present in Yamanaka's pool. NANOG was found to be dispensable for the reprogramming method used by Yamanaka, which can be explained by the fact that KLF4 upregulates NANOG [7]. After reprogramming, the retroviral transgenes become silenced and the endogenous genes encoding the four factors become

*Address correspondence to this author at Translational Cardiomyology, Stem Cell Institute Leuven, Katholieke Universiteit Leuven, Herestraat 49, PB814, 3000 Leuven, Belgium; Tel: +32 (0)16 3302 95;

Fax: +32(0)16 3302 94; E-mail: lieven.thorrez@med.kuleuven.be activated. Therefore, maintenance of pluripotency entirely relies on endogenous gene expression. Pluripotent stem cells are capable of indefinite self-renewal and have the ability to differentiate into all three germ layers (endoderm, ectoderm, mesoderm) and can thus give rise to all the cell types present in an adult organism. However, they cannot make extra-embryonic tissues such as the amnion, chorion, and other components of the placenta. Only the first few cells of the mammalian embryo are totipotent, capable of deriving all tissues and forming an embryo.

Pluripotent stem cell (PSC, encompassing both ESC and iPSC) colonies can be identified by analyzing the expression of pluripotency genes or cell-surface markers by QPCR, FACS analysis or immunostaining. Common markers include alkaline phosphatase, OCT4, SOX2, NANOG, TRA-1-60, TRA-1-81 and SSEA4 [8]. Functional proof that iPSCs truly have ESC properties can be shown both in vitro and in vivo and is based on the demonstration that iPSCs are capable of generating cells from all three germ layers. In vitro, iPSCs are cultured for about a week in suspension resulting in embryoid body (EB) formation followed by another week in culture on a gelatin-coated dish. After this time, spontaneous or induced differentiation into the different germ layers is monitored. In vivo, two tests have been used to assess pluripotency. A few weeks after injection in ectopic sites (e.g. subcutaneously in immunodeficient mice), PSCs form benign tumors, named teratomas, which contain multiple types of differentiated tissue derived from all three germ layers. The definitive test for pluripotency is the introduction of PSCs in a pre-implantation embryo followed by monitoring of the contribution of the PSCs to the chimaera.

The possibility to generate iPSCs from differentiated adult human cells with plasticity similar to that of ESCs has led to excitement regarding their potential to understand and treat disease. Similar to ESCs, iPSCs can be differentiated to all different cell types of which the body is composed. Especially for tissues that are difficult to obtain and/or culture, this has opened up completely new prospects for studying disease and developing treatments by regenerative medicine and drug screening. For these exciting prospects, reprogramming cells was chosen "Breakthrough of the year" in 2008 by Science magazine [9]. iPSCs have been differentiated in vitro to give rise to cardiomyocytes, adipocytes, osteoblasts, hematopoietic and differentiated blood cells, dendritic cells, macrophages, insulin-producing cells, hepatocyte-like cells, retinal cells 
and several types of neurons [10]. Here, we will focus on iPSCderived cardiomyocytes and their applications in the cardiovascular field. Fig. (1) represents a graphic overview of different aspects of iPSCs.

\section{GENERATING IPSCS: STRATEGIES AND CELL SOURCES}

\subsection{Strategies}

The reprogramming efficiency of adult human fibroblasts using the original Yamanaka method is below $0.01 \%$ and requires a minimum of 4 weeks to obtain expandable iPSC colonies after transduction [5]. Several adaptations to the retroviral transduction protocol led to improved reprogramming efficiency. These include exposure to a hypoxic environment, vitamin $\mathrm{C}$ addition, disruption of cell-cycle control checkpoints and expression of ES-cell specific microRNAs [11]. Although the original Yamanaka method using retroviral vectors containing the 4 factors currently remains the most widely used method, other reprogramming strategies have been developed. Different studies suggested that it is possible to reduce the number of factors required for iPSC generation and that small molecules can be used to replace the omitted factor(s). Expression of MYC was found to be dispensable for reprogramming, however at the cost of efficiency [12]. Omission of MYC is important for clinical applications, since reactivated retroviral expression of MYC was shown to increase tumorigenicity in progeny mice [12,
13]. Addition of valproic acid, a deacetylase inhibitor, allowed reprogramming with only OCT4 and SOX2 [14]. Recently, reprogramming of mouse fibroblasts was achieved with only Oct 4 and small molecules [15]. As a result of the reprogramming, the DNA methylation pattern changes such that somatic genes become silenced by methylation and pluripotency genes become activated by demethylation, as shown schematically in Fig. (2). It remains to be seen whether human cells can be reprogrammed with only OCT4 or even through purely chemical means. In the next paragraphs, we first discuss DNA-based strategies, followed by non-DNA based strategies.

The first reprogramming protocols relied on integrating vectors to insert the reprogramming genes into the genome of the somatic cell. To reduce the need for co-transduction of 4 retroviral vectors each carrying one reprogramming factor, a polycistronic cassette containing all four factors was designed to fit in a single lentiviral vector $[16,17]$. Insertion of DNA could interrupt existing genes, leading to aberrations such as tumor formation, as has been observed with retroviral gene therapy [18]. Excisable lentiviral vectors remove most of the transgene sequence but still leave a part of the lentiviral long terminal repeat integrated [19]. Other methods completely eliminate the use of integrating retroviral vectors. Adenoviral vectors do not insert into the genome and are diluted out as the cells divide, preventing genomic modification of the reprogrammed cells. Although nonintegrating adenoviral vectors were successfully

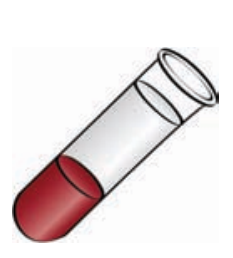

T-cells

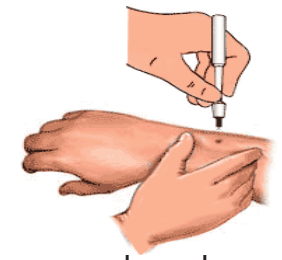

dermal

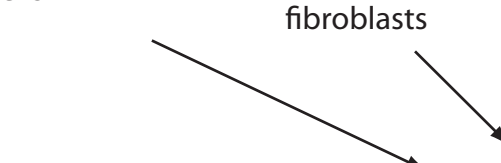

(2)
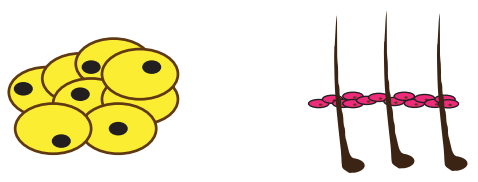

adipocytes

keratinocytes
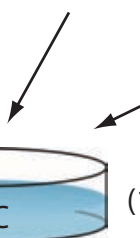

(1)

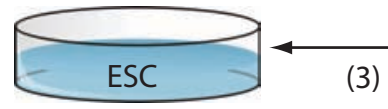

iPSC

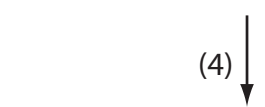

(5)

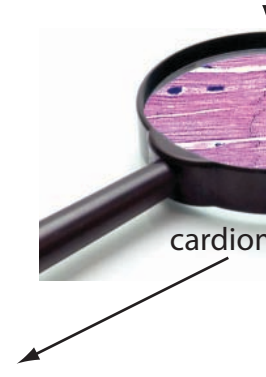

$(6)$

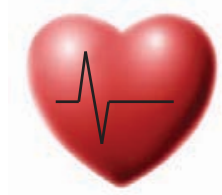

disease model

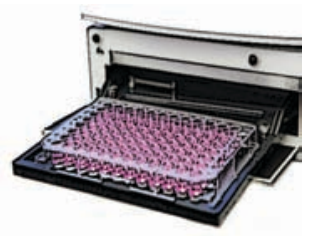

drug screening
(7)

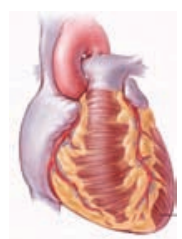

regenerative medicine

Fig. (1). Overview of iPSC generation, cardiomyocyte differentiation and applications towards cardiac therapy and drug development. Numbers between brackets indicate in which section each of the different aspects is further discussed. 
Differentiated cell $\quad$ iPSCs

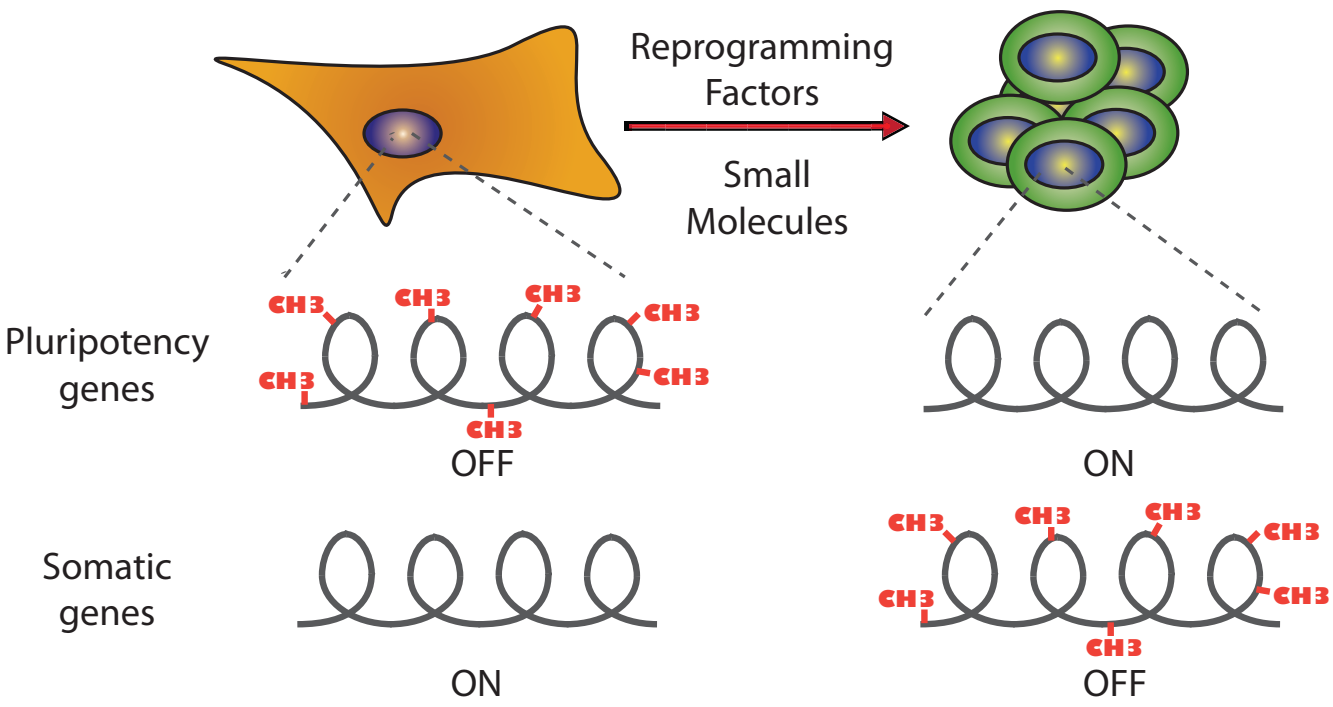

Fig. (2). Schematic representation showing the role of DNA methylation in reprogramming differentiated cells to iPSCs.

applied for reprogramming, they suffer from a low efficiency [20]. Virus-free reprogramming can be achieved by plasmid transfection [21], episomal vectors [22] or the bacteriophage $\Phi C 31$ integrase [23], which reduce the risk of genomic integration, but still have low efficiency. Excisable transposons based on Cre/Lox successfully removes transgene sequences, but leaves behind residual loxP sites and the risk of insertional mutagenesis remains. The PiggyBac transposon system, which requires only the inverted terminal repeats flanking a transgene and transient expression of the transposase enzyme to catalyse insertion or excision events, requires further development to achieve traceless removal of the transgenes $[24,25]$. Lastly, one recently described method does not rely on transfection of the known reprogramming factors, but works through overexpression of the miR-302 family [26]. This stimulates expression of the core reprogramming factors OCT4, SOX2 and NANOG while a loss of expression of multiple epigenetic regulators occurs, causing global genomic DNA demethylation. This method induces a quick reprogramming (5-6 days). However, all DNA-based methods still carry some risk of genomic recombination or insertional mutagenesis.

Virus- and DNA-free reprogramming has been achieved by protein or RNA-based approaches. Protein reprogramming eliminates the potential risks associated with viruses, DNA transfection and potentially harmful chemicals. The four reprogramming proteins were fused with a cell-penetrating peptide and delivered to human fibroblasts [27]. Generation of protein-induced iPSCs with this method is currently very slow and inefficient and generating the needed quantities of recombinant proteins is challenging. Transfection of human fibroblasts with messenger RNAs for the 4 factors, modified to overcome innate antiviral responses, results in a 36-fold higher reprogramming efficiency as with retroviral vectors [28]. RNA-derived iPSCs have a greater resemblance to human ESCs as retroviral-derived iPSCs. As an alternative to transfection, an approach involving the use of Sendai RNA virus was established $[29,30]$. These iPSC generating strategies are summarized in (Table 1).

\subsection{Cell Sources}

By now, iPSCs have been generated from a plethora of cell types. Here, we will briefly discuss a few cell types, listed in (Table 2), that are easy to obtain and thus might be a suitable source for future large-scale screening based on iPSC technology. Fibroblasts have mostly been used as a cell source for reprogramming, but are suboptimal for large-scale derivation of iPSC lines since local anesthesia, an incision and suturing is needed to obtain a skin biopsy. Reprogramming of juvenile human primary keratinocytes by retroviral transduction with OCT4, SOX2, KLF4 and MYC was shown to be 100-fold more efficient and twofold faster compared with reprogramming of human fibroblasts [31]. This cell type can be highly practical since single human hairs can be used to generate iPSCs, thus providing for an easily accessible cell source. Although the reprogramming efficiency reached $1 \%$, it is still unclear whether this could also be reached using adult human keratinocytes. T-cells can be easily obtained from peripheral blood and the efficiency of reprogramming is around $0.01-0.1 \%$, depending on the reprogramming method [29,31-34], therefore $1 \mathrm{ml}$ blood samples, which typically provide about a million T cells [34] are a feasible source. The impact of the presence of preexisting $\mathrm{T}$-cell receptor rearrangements on the properties of iPSC still needs to be determined. Hematopoietic stem and progenitor cells give rise to iPSCs up to 300 times more efficiently than terminally differentiated B and $\mathrm{T}$ cells, yielding reprogramming efficiencies of up to $28 \%$ [35]. $\mathrm{Hu}-$ man fat tissue can be obtained (sometimes in large quantities) by liposuction. This fat contains a heterogeneous group of multipotent progenitor cells that can differentiate into adipogenic, osteogenic, chondrogenic and myogenic cell lineages [36]. These progenitor cells can be reprogrammed into iPSCs with a 20 -fold greater efficiency $(0.2 \%)$ and 2 -fold faster as compared to adult fibroblast reprogramming [37].

It is clear that many cell types are amenable for reprogramming and a number of those are relatively easy to obtain. However, it is not entirely clear to what extent these cell sources are similar to ESCs and are able to reliably generate all differentiated cell types. These differences will be discussed in the next section. Future developments in iPSC technology are to be expected from the reprogramming methodology, based on a better understanding of what exactly happens during reprogramming. Attempts are being made to completely replace the reprogramming factors with a cocktail of defined small molecules that can induce reprogramming. However, if such an approach proves successful reprogramming, long-term effects of such molecules on genetic and/or epigenetic 
Table 1. iPSC Generating Strategies and Their Characteristics

\begin{tabular}{|l|c|c|c|l|}
\hline \multicolumn{1}{|c|}{ PROTOCOL } & INT & EFF & TIME & CHARACTERISTICS \\
\hline \hline Viral Vectors & & & & \\
Retroviral & + & ++++ & +++ & Retro: most widely used method \\
Lentiviral & + & ++ & ++ & Retro and lenti: stable integration \\
Adenoviral & - & + & ++ & \\
\hline Other DNA-based & & & & \\
Plasmid & - & + & ++ & Transient expression \\
Episomal vectors & - & ++ & ++ & Usually single integration \\
ФC31 & + & ++ & ++ & Excision not always traceless \\
Transposons & $(+)$ & ++ & ++ & \\
miRNA & - & ++++ & +++ & \\
\hline Non DNA-based & & & & \\
RNA transfection & - & ++ & + & Avoid genomic insertion but high cost, slow and inefficient \\
RNA vector & - & ++ & ++ & \\
Proteins & - & + & + & \\
\hline
\end{tabular}

INT= genomic integration (+ integration in the genome, - no integration), EFF= efficiency in terms of percentage of cells reprogrammed. TIME $=$ time need to achieve reprogramming. ++++ highest (fastest), +++ high (fast), ++low (slow), + lowest (slowest). Note that reprogramming efficiency and timing is highly influenced by cell source and ageing.

Table 2. Cell Sources Used for the Generation of iPSCs

\begin{tabular}{|l|l|l|}
\hline \multicolumn{1}{|c|}{ CELL TYPE } & \multicolumn{1}{c|}{ EFF } & \multicolumn{1}{c|}{ SOURCE, CHARACTERISTICS } \\
\hline \hline Fibroblasts & ++ & From skin, need small surgical procedure \\
\hline Keratinocytes & +++ & From hair, very easy to obtain \\
\hline T-cells & ++ & From blood, easy to obtain \\
\hline Adipocytes & +++ & From fat, obtained after liposuction \\
\hline EFF= efficiency in terms of percentage of cells reprogrammed. +++ high, ++ moderate. Note that reprogramming efficiency is also highly influenced by the reprogramming method
\end{tabular}

alterations to the target cells will need to be thoroughly investigated.

\section{COMPARISON TO ESCS: GENETICS \& EPIGENETICS}

A major limitation for use of ESCS is based on ethical concerns because an embryo is destroyed to obtain the ESCs. This has led to fierce debates over their use for scientific research and will be even of greater concern for patentability issues and further commercial use of ESC technology [38]. Another disadvantage of ESC-derived cells is transplant rejection due to immunological mismatch between the ESCs and the recipient. The use of patient-specific iPSCs could address both of these concerns. However, recent findings suggest that iPSCs are different from ESCs.

Already with the first description of (murine) iPSCs, it was stated that they are not identical to ESCs, since they had a lower expression of Dnmt3a, Dnmt3b, Dnmt3l, Utf1, Tcl1, and the LIF receptor gene [4]. Comprehensive analyses of various ESC and iPCS lines showed that iPSCs differ from ESCs at the molecular level when comparing gene expression signatures [39,40]. When comparing multiple transcriptional datasets from human fibroblasts, ESCs and iPSCs derived from fibroblasts, it was found that iPSCs shared four times more genes in common with fibroblasts than ESCs [41]. Besides differences at the level of mRNA expression, also microRNA expression was shown to differ between iPSCs and ESCs, with some cancer related microRNAs highly expressed in iPSCs $[40,42]$. In murine iPSCs residual DNA methylation signa- tures characteristic of their somatic tissue of origin, favored differentiation along lineages related to the donor cell, while restricting alternative cell fates $[43,44]$. This indicated that iPSCs retain some epigenetic memory of the somatic cells from which they were derived. For example, skeletal muscle mesoangioblast-derived iPSCs demonstrated a strong myogenic commitment since teratomas contained $70 \%$ striated muscle tissue versus $5 \%$ for fibroblast-derived iPSCs [45]. Importantly, the former could more efficiently participate to skeletal muscle regeneration in a dystrophic disease mouse model. Differentiation, serial reprogramming or treatment with chromatin-modifying drugs could reset the epigenetic memory. Similar effects of epigenetic memory have been described in human iPSC lines [46,47]. Passaging of human iPSC cell lines has been shown to push their gene expression profile towards that of ESCs and erase the epigenetic memory [40,44]. When genetically identical mouse ESCs and iPSCs were compared, overall messenger RNA and microRNA expression patterns were indistinguishable with the exception of a few transcripts encoded within the imprinted Dlk1-Dio3 gene cluster, which was aberrantly silenced in most of the iPSC clones [48]. These clones failed to support the development of iPSC-derived animals, in contrast to iPSC clones with normal expression of the Dlk1-Dio3 cluster, which had the full development potential of ESCs. Clones with the silenced Dlk1-Dio3 locus could be rescued with a histone deacetylase inhibitor, which reactivated the locus and rescued its ability to support full-term development of iPSC-derived mice. Interestingly, by reanalyzing iPSC and ESC microarray gene expression data 
from different laboratories, it appears that iPSCs and ESCs from individual labs cluster tightly together, whereas most variation is observed between different labs [49]. This indicates that differences in culture conditions significantly affect gene expression differences and that these differences are larger than those between ESCs and iPSCs.

Very recently, genetic and epigenetic defects in iPSCs were studied in detail at the level of chromosome number [50], copy number variation $[47,51]$, point mutations [52] and DNA methylation [46]. Aneuploidy was detected mainly in early passage iPSCs [50], which is likely due to considerable selective pressure during the reprogramming process and is reminiscent of chromosome instability, which is commonly observed during early human embryogenesis [53]. Similarly, copy number variations were found to occur at a relatively high frequency in early-passage iPSCs, but expansion of iPSCs selected against the mutated cells drives the lines towards an ES-cell like state [47]. Human iPSCs were found to contain more deletions whereas ESCs had more gains compared to somatic cells [51]. It was estimated that on average 6 proteincoding point mutations occur in iPSC lines, thought to be induced mainly by iPSC colony picking and subsequent culturing [52]. Methylation patterns near the centres and ends of chromosomes in the iPSCs resembled those in the tissues from which the iPSCs were derived [46], explaining whyCpG methylation patterns were found to differ between iPSCs and ESCs [54]. Overall, from these studies can be concluded that iPSCs display more genetic and epigenetic abnormalities than ESCs or the fibroblasts from which they originated. The amplifications, deletions and point mutations seem to be enriched in genes involved in cell cycle regulation and cancer [55].

Besides somatic cell origin, the reprogramming method influences differences between iPSCs and ESCs. Reprogramming by non-integrating methods generate iPSCs that are more similar to ESCs than those generated with integrating viral vectors [41]. No obvious correlation has been found between the reprogramming method and the extent of genetic damage in a given iPSC population [55].

As for cardiomyocytes derived from ESCs and iPSCs, the global transcriptomes of beating clusters differentiated from both were compared and found to be similarly enriched for cardiospecific genes and overall highly similar [56]. In addition to the transcriptional similarities, sarcomeric organization, electrophysiological characteristics and calcium handling properties were indistinguishable. Expression profiles differed in $1.9 \%$ of present transcripts, indicating more abundant expression of extracellular matrix components and cell adhesion molecules, significantly overlapping with the gene signature of undifferentiated iPSCs versus ESCs. This could represent a set of fibroblast-associated genes that remain expressed in iPSCs because they are refractory to silencing during reprogramming. It was not determined whether these differences were due to a different cellular composition of the beating clusters and/or due to retention of some somatic cell gene profile in differentiated iPSC-derivatives. Single cell analysis of iPSC lines revealed a greater heterogeneity in gene expression compared to ESC lines [57]. Also, iPSC colonies displayed increased ectodermal lineage priming in the periphery whereas this was not observed with ESC colonies. In addition, ESCs could be differentiated more robustly to cardiomyocytes than iPSCs [57]. For obtaining a robust differentiation of iPSCs to cardiomyocytes, it is desirable to use a cell source that is as closely related to cardiomyocytes as possible. Alternatively, one can take advantage of the epigenetic memory; when a completely different cell source is used for iPSC generation, this iPSC may be differentiated (at low efficiency) to the desired cell type, from which in a second round again iPSCs are derived which then can be differentiated at higher efficiency [43].

Despite the differences between ESCs and iPSCs, the differentiation protocols developed for ESCs are also applicable for iPSCs.

\section{CARDIOMYOCYTE DIFFERENTIATION PROTOCOLS}

Insights from developmental biology can now be applied towards the differentiation of PSCs into cardiomyocytes. The development of cardiomyocytes after gastrulation can be summarized as formation of mesoderm ( $T$ or mouse Brachyury homolog, FOXC1, DKK1), cardiogenic mesoderm (MESP1, ISL1, KDR (Flk1 in mouse), cardiac mesoderm (NKX2.5, GATA4, TBX5, MEF2C, $H A N D 1 / 2$ ) and maturation of cardiomyocytes (ACTN1, MYH6, TNNT2). Initial differentiation protocols were developed for ESCs derived from donor blastocysts. More recently, these protocols have been successfully applied for differentiation of iPSCs. Over time, the capability to control stem cell differentiation towards cardiomyocytes has improved such that nowadays many protocols exist to obtain stem cell derived cardiomyocytes. However, depending on the stem cell sources and other (sometimes unknown) variables, the efficiency can greatly vary. This is not only in terms of the number or percentage of cardiomyocytes obtained, but also in terms of the duration of the differentiation protocol, and the presence of other differentiated cell types besides the cardiomyocytes. In addition, three different cardiomyocyte subtypes exist: ventricular, atrial and pacemaker cells. There exist 3 methods to differentiate PSCs to cardiomyocytes: spontaneous differentiation of embryoid bodies, co-culture with mouse endoderm-like cells (END2), and the cardiac differentiation induced by defined growth factors [58].

The first developed method to obtain cardiomyocytes was by spontaneous differentiation of embryoid bodies. PSCs are cultured in suspension for about 8 days in differentiation medium, which induces EB formation and then EBs are further cultured on gelatincoated dishes for another 8-10 days [59]. The EBs contain cell types derived from mesoderm, but also ecto- and endoderm. Within these mixed populations, contracting cardiomyocytes can be detected. This method was successfully applied to iPSCs [60], but with variable and low $(<10 \%)$ efficiency of cardiomyocyte formation, since only a minority of EBs develop cardiomyocytes and only small regions contain contracting cardiomyocytes. Size of the EBs is an important variable and slightly more reproducible results can be obtained by using the hanging drop method [61], centrifuging a defined number of cells (forced aggregation method) [62] or microprinting [63]. The efficiency to generate cardiomyocytes can be further enhanced by using the demethylating agent 5-azacytidine during the first 3 days [61] and by incubation in hypoxia [63].

The spontaneous EB differentiation is relatively simple and inexpensive and therefore remains widely used. However, due to the variability in terms of generating various cell types, it is not optimal to obtain cardiomyocytes for further in vivo applications or even in vitro drug screening. A more efficient way to generate cardiomyocytes is by coculture of human ESCs with endodermal (END2) cells, which are mouse embryonal carcinoma cells [64]. This method generates cardiomyocytes with fetal ventricular characteristics in 12 days with an efficiency of $5-20 \%$. This protocol is most efficient in serum-free medium [65] and can be optimized by using END2 conditioned medium, and by adding a P38MAPK inhibitor in a 12-day suspension culture. This results in $\geq 20 \%$ cardiomyocytes with both ventricular and atrial characteristics [66]. Cyclosporin-A has been described to increase the induction of cardiac progenitors as well as cardiomyocytes from mesoderm by 10-20 times [67] and combined with the END2 coculture, this further increased the number of beating colonies [68]. Insulin is rapidly cleared by medium conditioning, and although it has been shown to inhibit cardiogenesis, omission was not sufficient to induce it [69]. The END2 cells secreted high levels of prostaglandin $\mathrm{I} 2$ and when this was added to a fully synthetic, insulin-free medium, cardiogenic activity was equivalent to conditioned medium [69].

Recent methods use more refined strategies to guide differentiation and therefore rely on combined and sometimes serial use of several growth factors $[5,70,71]$. Cardiac development is tightly 
orchestrated by sequential expression of different sets of genes. These factors work in a certain time window and when expressed beyond this time window, they may block further development. Therefore, understanding natural cardiomyogenesis is critical for setting the time of addition and withdrawal of certain factors during guided differentiation. Currently, only the initial step of differentiation from PSCs to mesoderm is reasonably well characterized. This step involves WNTs, BMPs and Nodal or activinA [72]. By treating a monolayer of ESCs on Matrigel-coated plates for 1 day with activin A followed by 4 days of BMP4 exposure, $>30 \%$ cardiomyocytes could be obtained [70]. The total protocol takes about 1 month, but widespread spontaneous beating activity could be observed 12 days after addition of activin A. Another guided differentiation protocol was described [71], also using a serial exposure to BMP4 and activin A plus bFGF during the first 4 days, but then followed by the WNT inhibitor DKK1 and VEGF. Embryoid bodies generated in this way contained $40-50 \%$ cardiomyocytes at day 16. When they were FACS sorted at day 6 for the $\mathrm{KDR}^{\mathrm{low}} / \mathrm{cKit}^{-}$cell population, containing the cardiac progenitors and then plated in monolayer, $57 \pm 4 \%$ cardiomyocytes were obtained along with smooth muscle and endothelial cells. Instead of BMP4, a 2-day exposure to WNT3A can be used to induce mesendoderm formation, which was described to be more effective at stimulating cardiomyogenesis, although this effect could partly be mediated by the suspension culture instead of monolayer culture [73]. Together with the gradual reduction of serum and insulin levels in the differentiation medium, this leads to the generation of $50 \%$ cardiomyocytes in the beating clusters within 16-23 days. A 6-day treatment with BMP2 (which strongly induces WNT3A) and an FGF receptor inhibitor also drives human ESCs and iPSCs into cardiac commitment [74]. About half of the resulting progenitor cell population then expresses stage-specific embryonic antigen 1 (SSEA1), one of the earliest markers of PSC differentiation and loss of pluripotency. The sorted SSEA $1^{+}$population was then cultured on MEFs for 5 days and could be differentiated to cardiomyocytes, endothelial and smooth muscle cells by plating on fibroblasts or incubation with VEGF or PDGF, respectively. Also noteworthy for this protocol (tested on rhesus ESCs) is that by co-culture with a mix of (human) cardiomyocytes and cardiac fibroblasts (or the conditioned medium), ESC-derived cardiomyocytes adapt an adult ventricular phenotype with mature sarcomeres. A handful of small molecules that stimulate cardiomyogenesis from PSCs have been described, including cardiogenols (induces GATA4 and MEF2C), ascorbic acid (hypoxia and Notch signaling), sulfonyl hydrazones (increases T), DMSO (chromatin remodeling) and isoxazolyl-serines [75]. Besides transcription factors, expression of microRNAs also determine ESC fate by the regulation at the posttranscriptional level. miR-1 increases the proportion of beating aggregates and miR-133 promotes early mesoderm differentiation, but then inhibits further cardiac commitment [76].

None of the above described protocols leads to a homogenous, well-characterized population of cardiomyocytes. However, it is possible to isolate the cardiomyocytes from a heterogeneous pool of different cell types. Microdissection and Percoll density centrifugation have been widely used, but these methods are labor intensive and still do not provide high purity. Transgenic selection techniques have been employed for cardiomyocyte enrichment by insertion of a reporter gene and/or an antibiotic resistance gene under the transcriptional control of a cardiac specific promoter [58]. This typically results in cardiomyocyte enrichment $>90 \%$, but the genetic modification may provide a hurdle for further clinical applications. An efficient and straightforward method is based on the characteristic of cardiomyocytes to have many mitochondria. A fluorescent dye that labels the mitochondria can be used to sort out cardiomyocytes to $>99 \%$ purity, without the need for genetic modification [77]. At present, it is not entirely clear whether a pure population of cardiomyocytes is needed for downstream in vivo or in vitro applications.
Of note, mouse cardiomyocyte-like cells can also be derived from embryonic [78] and cardiac or dermal [79] fibroblasts, without going through an iPSC stage, a process called transdifferentiation. Whether this is feasible for human cells remains to be demonstrated. However, the dermal fibroblast-derived cardiomyocytes displayed limited functionality [79].

Taken together, although a number of cardiac differentiation protocols have been described, those will likely need to be optimized for each specific PSC line [80]. Stem cell derived cardiomyocytes at present have an immature phenotype compared to adult cardiomyocytes, apparent by the expression of certain markers and their functional characteristics. ESC-derived cardiomyocytes were reported to display negative force-frequency relations (versus a positive relation in the adult myocardium) and different intracellular calcium handling properties due to an immature sarcoplasmic reticulum [58]. This may affect their use for drug screening as well as their usefulness and safety for in vivo repair strategies (section 7). Therefore, current protocols still need further optimization to control in vitro maturation as well as differentiation towards the desired subtype.

\section{APPLICATIONS OF IPSCS FOR MODELING OF CAR- DIAC DEVELOPMENT AND CARDIAC DISEASE}

It can be foreseen that developmental biology and stem cell differentiation will move forward through mutual beneficial interactions between both fields. High-throughput screening (expression microarrays, sequencing, ChIP-chip,...) can now be used to comprehensively characterize mRNA and microRNA expression as well as epigenetic changes such as chromatin modifications and DNA methylation. Combined with systems biology tools to integrate all these data, this can lead to a characterization of heart development at different stages. Such an approach was recently described, where the combinatorial contribution of Gata4, Mef2a, Nkx2.5 and Srf and the interdependency with histone modifications and microRNAs in regulating the cardiac transcriptome was shown [81]. Also the ability to perform analysis at the single cell level may provide insights in morphogen gradients leading to cellular heterogeneity and spatial organization. These insights can then be verified in a controlled environment by recapitulating development on PSCs. To date, there is no consensus on the best marker for identification of adult cardiac stem cells and the mechanisms promoting their selfrenewal and the differentiation into the various lineages of the heart remain largely unknown [82]. iPSC can provide a model system to test hypotheses regarding these mechanisms. A better understanding of the factors involved can potentially lead to therapies wherein residing stem cells are reactivated and differentiated to the desired cell type(s) following acute or chronic disease.

Patient-specific iPSC technology provides a new platform for decoding mechanism of disease [10]. They can be differentiated to the cell type(s) of interest and disease characteristics can be studied independent of environmental factors. Alternatively, the effect of environmental factors can be tested in a controlled way. Recently, disease-specific iPSCs have been shown to be a good model to study cardiomyopathy and drug response. Cardiomyocytes differentiated from iPSCs, which were derived from patients with long QT syndrome (LQTS), a cardiac disorder characterized by arrhythmias that can lead to sudden death, displayed several aspects of the disease: a prolongation of the action potential and the presence of early depolarizations $[83,86]$. Mutations in at least 12 different ion channels or associated proteins have been linked to congenital LQTS, with an estimated prevalence of $1 / 7000[85,86]$. In the case of LQTS type 2, the gene for the hERG (human Ether-a-go-go) potassium channel $(\mathrm{KCNH} 2)$ is mutated [83]. Several drugs that target different ion channels prevented arrhythmias in the iPSC-derived cardiomyocytes [83]. Moreover, when treated with cisapride, a drug that was pulled from the market for causing lethal arrhythmias, the cells beat more irregularly [83]. In LQTS type 1, mutations occur in 
the $K C N Q 1$ gene coding for the repolarizing potassium channel. Cardiomyocytes derived from iPSCs containing such mutation had $>70 \%$ reduction in $\mathrm{I}_{\mathrm{KS}}$ current and altered channel (de-)activation properties [84]. These cells had an increased susceptibility to catecholamine-induced tachyarrhythmia, which could be attenuated with beta-blockade [84]. A third report described an iPSC-based model of LQTS in Timothy syndrome patients [85]. Timothy syndrome is caused by a mutation in CACNAIC, the gene encoding the main L-type channel in the mammalian heart. Cardiomyocytes from these iPSCs also displayed the molecular hallmarks of LQTS and treatment with roscovitine restored their electrical and $\mathrm{Ca}^{2+}$ signaling properties. Besides LQTS, other cardiac disorders can also be studied; a recent example is the generation of iPSC-derived cardiomyocytes from patients with LEOPARD syndrome. This syndrome is due to a mutation in the PTPN11 gene, which encodes the SHP2 phosphatase. LEOPARD is the acronym for its main features: lentigines, electrocardiographic abnormalities, ocular hypertelorism, pulmonary valve stenosis, abnormal genitalia, retardation of growth and deafness [87]. Of these features, hypertrophic cardiomyopathy is the most life threatening. Cardiomyocytes from these iPSCs were found to be larger, and to have a higher degree of sarcomeric organization when compared to normal, which correlates with the hypertrophic state. It is worthwhile noting though that some of the standard procedures to analyze cardiomyocyte hypertrophy could not be reliably assessed due to the mixed population of cells obtained with the cardiac differentiation procedure. Nevertheless, this model provided valuable insights in the affected downstream signaling pathways [87]. Disease-specific iPSCs from patients with other heart diseases such as Brugada syndrome, catecholaminergic polymorphic ventricular tachycardia, arrhythmogenic right ventricular cardiomyopathy and other genetic arrhythmias may shed some light on these disease mechanisms and perhaps result in the discovery of new therapies [88].

However, it is not clear whether iPSCs will be suitable to study adult-onset diseases, since ageing and disease effects in chronic conditions may be mediated by epigenetic modifications on gene expression. As current iPSC technology erodes epigenetic signatures, this cell memory may be lost, both in the iPSCs themselves and their derivatives, restricting the use of iPSCs at present to study genetic diseases.

\section{APPLICATIONS OF IPSCS FOR CARDIAC DRUG DE- VELOPMENT}

Several drugs have been withdrawn from the market because of safety concerns. In some cases, numerous injuries or even deaths occurred, before these drugs were ultimately withdrawn from the market. Late stage attrition is mainly due to the lack of unexpected safety issues of these new compounds [89]. All new drugs, not only those developed for cardiovascular applications, need to be screened for negative side effects on the human heart. Clearly, there is a need for reliable and sensitive methods to assess this, preferably via high-throughput screening.

In humans, cardiomyocytes (as well as other pharmaceutically relevant cell types such as hepatocytes and neural cells) are not easily accessible without performing highly invasive procedures. In addition, only limited amounts of cardiomyocytes can be obtained, which cannot be kept in culture for an extended period of time and these cells do not beat spontaneously. Isolation of cardiomyocytes or entire hearts from animals may allow for higher throughput screening as compared to in vivo animal testing, but this does not resolve the ethical issues. Moreover, species differences between humans and the animal model may still result in inaccurate conclusions. Currently, no good animal models exist to study the effect of drugs on heart function, because rodent hearts beat much faster than the human heart and use different ion channels [90]. As a substitute, several models exist in which human ion channels such as hERG are overexpressed. However, these cell lines still significantly differ physiologically from adult human cardiomyocytes. The hERG channel is part of a complex that includes auxiliary subunits, regulatory proteins and potentially other ion channels [86]. Therefore, studying hERG channels in heterologous systems, such as those that are currently widespread in heart toxicity screenings, may fail to recapitulate their behavior in the human heart. A model system in which the hERG channel is present in human cardiomyocytes may thus improve the reliability of drug screening for cardiotoxicity.

Despite the aforementioned immature phenotype of PSCderived cardiomyocytes, they still provide a useful model. They exhibit depolarization patterns with action potentials typical for cardiomyocytes [58]. Importantly, PSC-derived cardiomyocytes are responsive to hormonal treatments, which reveals functional adrenergic and muscarinic receptors. Their electrophysiological utility is underscored by the expression of many essential ion channels for action potential repolarization, including the cardiac sodium channel SCN5A, the voltage-dependent L-type $\mathrm{Ca}^{2+}$ channel CACNA1C and the voltage-gated $\mathrm{K}^{+}$channels KCNA4 and KCNH2 (hERG) [58]. Moreover, maturation to an adult phenotype was demonstrated with human ESC-derived cardiomyocytes by keeping them in culture for three months [91].

Assessing risk for QT interval prolongation is part of the standard preclinical evaluation for all novel drugs in development, as defined by the International Conference of Harmonization Expert Working Group [92]. The studies described in the previous section [83-85] provide evidence that human iPSC-derived cardiomyocytes can be used to screen for drug-induced LQTS, one of the most common forms of drug toxicity by blocking hERG [86]. Druginduced LQTS is a side effect of many approved drugs and is a common cause of drug failure in clinical trials [85]. Non-diseased human iPSC-derived cardiomyocytes have been analyzed for their response to ion channel inhibitors using a microelectrode array. Microelectrode arrays can be used to measure local changes of the membrane potential of cardiomyocytes and provide an attractive alternative to patch-clamp analysis since they are amenable to highthroughput screening. Dose-dependent changes to the field potential waveform were observed for several cardiac and non-cardiac drugs, identical to those induced in native cardiomyocytes [93,94]. This confirms the value of the model for cardiac electrophysiologic studies and drug screening. A limitation with the described approach is the use of spontaneously differentiated EBs. The clusters contain a heterogeneous population of cells and clusters differ in size, beat frequency and cellular composition, leading to considerable variation and lack of reproducibility [58]. As for drug discovery, this model likely will allow for finding drugs that act specifically on cardiomyocytes, such as heart muscle strengthening (inotropic) drugs and small molecules promoting cardiomyocyte differentiation of endogenous adult progenitor cells.

Cellular Dynamics International was the first company to sell iPSC-derived cardiomyocytes. Their $\mathrm{iCell}^{\circledR}$ cardiomyocytes are produced from a single clonal population of iPSCs reprogrammed by lentiviral transfer [6]. These cardiomyocytes are amenable to assay cell viability, apoptosis, ATP production, oxidative stress, mitochondrial dysfunction and for electrophysiological applications such as patch clamp and microelectrode assay recording. Recently, the company teamed up with Roche to use the $\mathrm{iCell}^{\circledR}$ cardiomyocytes on microtiter plates containing microelectrodes which record real-time fluctuations in impedance that can then be related to cell health and physiological activity. Other companies, such as iPierian and Fate Therapeutics are already using iPSC technology as a model to find new molecular targets and develop compounds for diseases with currently limited treatment options and poor in vivo and in vitro models.

iPSC-derived cardiomyocytes possess the complete molecular machinery necessary for proper function, including the contractile apparatus, intercellular communication structures, ion channels, and receptors for hormonal regulation of heart function [95]. Neverthe- 
less, cardiac cells derived from PSCs generally show immature phenotypes. The maturity, as well as the mix of cells with atrial nodal or ventricular characteristics is highly dependent on the differentiation protocol. Most protocols based on EBs result in a mix of atrial, ventricular and nodal cardiomyocytes. Using the END2 coculture, cells are comparable to week 16 fetal cardiomyocytes with the majority displaying a ventricular phenotype $[64,65,95]$. Replating of cardiomyocytes, followed by a short 3D culturing step resulted in maturation in terms of electrophysiological properties and selection towards pacemaker cells [96]. The 3D culturing accelerated maturation by restoring the global gene repressive status established in the adhesive status. Also, the influence of other cell types on cardiac differentiation and characteristics of cardiomyocytes is currently not completely understood and using pure cardiomyocyte populations may not accurately reflect the in vivo situation. Early isolation of ESC derived cardiomyocytes without further interaction with non-cardiomyocytes was shown to inhibit ion channel development and electrophysiological maturation [97]. No matter how closely iPSC-derived cells match their in vivo counterpart, single cell culture systems may still not be a reliable model, since they are not in contact with other cells and factors that modulate disease or drug response and may not accurately reflect physiological endpoints. Tissue engineering approaches can in part remedy these shortcomings. Engineered heart tissue has been created by mixing neonatal rat heart cells in a fibrin matrix, attached to flexible posts [98]. This approach, based on a screening technology for skeletal muscle [99], can be used to calculate rate, force and kinetics of the rhythmic contraction that starts after 8 to 10 days. Other tissue engineering approaches such as allowing the cells to undergo cyclic stretch may enhance maturity [100].

Besides their application in toxicity screening, iPSCs can be used in high content screening for the discovery of small molecules that activate signaling pathways involved in cardiogenesis. Advantages of small molecules include their membrane penetration, rapid activation or inhibition of targets, the reversibility of their activity, and the potential for modulating multiple targets. Such molecules can then be used for more efficient in vitro differentiation protocols, enhancements to cell therapies or for direct action on resident stem cells in the patient.

Towards the future, iPSC-derived cells and tissues should be further integrated in dedicated high content screening devices to address relevant parameters. Currently, most screening devices use monolayer cultures. Cardiomyocyte maturation potential and functional properties of cells (such as force generation) in a $2 \mathrm{D}$ environment, mostly on hard plastics, may be very different from a 3D environment. Therefore, high content screening devices will need to be adapted to fully capture information from such 3D constructs. When iPSC-derived cardiomyocytes will become available from a broad set of genetic backgrounds, pharmaceutical companies will be able to identify drug treatments that are effective or have a side effect in only a subgroup of patients. Generating personalized iPSCs is too time-consuming and expensive with the current technologies [90]. However, testing drugs on subsets of patients will likely lead to the identification of markers that could allow optimization of therapies for a given mutation.

\section{APPLICATIONS OF IPSCS FOR REGENERATIVE CAR- DIAC THERAPY}

The long-term goal of regenerative medicine is to repair or replace tissue structures that have been impaired by disease. Adult human cardiomyocytes have a very limited proliferative capacity that is not sufficient to repair larger areas of damaged heart e.g. after an ischemic event. Cardiomyocyte death is followed by fibrosis, resulting in scar tissue. To prevent scar formation, it would be highly desirable to either induce resident progenitor cells to differentiate into cardiomyocytes or to replace dead cardiomyocytes with stem cell-derived cardiomyocytes. Autologous iPSC-derived cells or tissues avoid host/donor incompatibility and eliminate the need for immunosuppression and cytotoxic medications, which are currently required to prevent rejection of allogeneic tissue. For in vivo cardiovascular therapy, iPSC-derived cardiac stem cells or differentiated cardiomyocytes are very attractive, however, their use in humans is hampered by major safety concerns. First, iPSCs have the capacity to generate teratomas. Even when iPSCs are first differentiated in vitro, protocols will need to completely exclude the possibility that a minor population of iPSCs remains in the differentiated population. The possibility of teratoma formation from the remaining undifferentiated cells is one of the most important issues in cell therapy with iPSCs. Further analysis of the therapeutic potential of iPSCs and their progeny and of teratoma or tumorforming propensity in animal models with long-term follow-up is therefore required before cell therapy with human iPSCs can advance to clinical trials [88]. Second, progenitor cells may start to proliferate in an uncontrolled manner and result in tumor development. On the other hand, using cells in a too differentiated stadium may limit their therapeutic benefits for several reasons: a lack of plasticity and ability to differentiate in the cell types needed for optimal repair, limitations in the number of cell divisions or limitations in paracrine signaling potency. Although certain fish and amphibians retain a robust cardiac regeneration capacity throughout life, this does not happen in the adult mammalian heart. Recently, it was demonstrated however that this capacity is present in the heart of 1-day old neonatal mice, which can regenerate after partial surgical resection [101]. Whether this holds true for humans is not entirely clear, however, this information may implicate that iPSCderived cardiomyocytes might be most suitable for cardiac repair when they have the phenotype of early postnatal or prenatal cardiomyocytes.

Myocardial infarction, with sudden loss of oxygenated blood to the heart, leads to massive cell death, a transient pro-inflammatory environment and permanently injured myocardium. Many studies have been carried out with human ESC-derived cardiomyocytes or cardiac progenitors transplanted into the infarcted hearts of rodents and were shown to improve cardiac function [88]. When mouse fibroblast-derived iPSCs were transplanted to the injured region 30 minutes after myocardial ischemia, improved cardiac contractility was observed at 4 weeks [102]. Successful iPSC treatment prevented structural remodeling and avoided the deleterious effects on electrical conductivity. Surgical dissection verified the absence of teratoma or dysregulated cell expansion [102], however, others have observed teratoma formation following a similar treatment and recommend differentiation into the cardiac lineage prior to transplantation [103]. Indeed, $\mathrm{Is}^{+} 1^{+}$multipotent cardiovascular progenitors from mouse iPSCs were shown to spontaneously differentiate in all 3 cardiovascular lineages after transplantation in the left ventricular wall of nude mice, without teratoma formation. Moreover, human iPSC-derived Is $11^{+}$progenitors with similar developmental potential have been described [104]. Early cardiac progenitor cells expressing SSEA1 are capable of generating cardiomyocytes, endothelial cells and smooth muscle [74]. Selection for the $\mathrm{SSEA}^{+}$cells was critical, since transplantation with $\mathrm{SSEA}^{-}$cells resulted in teratoma formation, whereas a purified SSEA $1^{+}$population did not. SSEA1 is a marker for loss of PSC pluripotency, so SSEA1 ${ }^{-}$cells represent the cell fraction that did not respond to morphogen treatment and retained pluripotency. When transplanted in a primate cardiac infarction model, the SSEA $1^{+}$cells differentiated into mature ventricular cardiomyocytes that responded to electrical stimulation. Although the transplanted cells repopulated $20 \%$ of the scar area, no data were shown indicating a functional benefit of this cell therapy. Interestingly, with the described protocol, no pacemaker cells were formed in vitro, which is likely advantageous for in vivo repair, since the ectopic introduction of pacemaker cells may induce arrhythmogenicity. Cardiomyocytes, however, may turn out not to be the most suitable cell type for functional repair after an ischemic event. By lineage-specific depletion 
experiments after bone marrow-derived cell transplants, it was shown that endothelium- or smooth muscle-committed cells, but not cardiac committed cells, were responsible for ejection fraction improvement [105].

Little attention has been given to the generation of cardiac fibroblasts. It has been determined by FACS analysis that the adult murine myocardium is composed of about $56 \%$ cardiomyocytes, $27 \%$ fibroblasts, $7 \%$ endothelial cells, and $10 \%$ vascular smooth muscle cells [106]. The primary function of cardiac fibroblasts is the synthesis and maintenance of an extracellular matrix, which forms a 3D scaffold for the cardiomyocytes. This scaffold distributes mechanical forces throughout the myocardium and integrates the contractile activity of individual cells to coordinate the pump function of the heart [107]. Cardiac fibroblasts secrete autocrine and paracrine factors that control cardiomyocyte growth [108]. In addition to its primary structural role, the ECM can also act as a repository of growth factors. Cardiac fibroblasts also function as mechano-electric transducers that are possibly involved in the mechano-electric feedback mechanism of the heart [109]. The presence of cardiac fibroblasts may therefore be required especially for tissue engineering applications where the deposition of an autologous extracellular matrix is warranted. Support of biodegradable scaffolds, as for example has been described for myoblast transplantation [110], has not been much explored in the context of iPSCs. Such scaffolds could be used to release additional growth factors to sustain cell survival, induce cell differentiation, as well as fixing the regenerative cells at the injured sites. Other tissue engineering approaches, such as electrical or mechanical stimulation or stacking of cell sheets, may apply to generate tissue patches for cardiac repair [111]. A limitation with tissue-engineered constructs is often the lack of effective vascularization. Scaffolds and/or extracellular matrices can also be used to secrete angiogenic molecules to enhance vascularization around the transplanted cells [112]. The presence of fibroblasts and endothelial cells next to cardiomyocytes in engineered cardiac tissue was shown to enable the formation of microvessels, which could anastomose with the vasculature of mouse recipients [113].

Besides cardiac ischemia, iPSCs can also be used to treat peripheral ischemia as indicated by induced revascularization, paralleled with increased $V E G F$ mRNA expression, after transplantation of FLK $1^{+}$iPSCs in a hind limb ischemia model [114]. Also, other applications of iPSCs are being explored, such as the creation of a biological pacemaker. Therefore, cells with the right electrophysiological characteristics are needed, which in practice, translates into an enriched population of nodal cells [96]. Activation of $\mathrm{Ca}^{+}$activated potassium channels by 1-ethyl-2-benzimidazolinone drives murine ESCs towards pacemaker-like cells [115]. Although all small-conductance $\mathrm{Ca}_{2}^{+}$-activated $\mathrm{K}^{+}$channel isoforms can be detected in human iPSCs, the functional role of this particular ion channel family in the human system is not yet entirely clear.

For certain monogenetic diseases, genetic correction of the defect in the iPSC line before transplantation will be needed. In order to attain a permanent correction, modification of the genome e.g. by retroviral or lentiviral vectors is warranted. As discussed above, these integrating vectors carry some risks. Hyperactive transposons may be an attractive alternative as they reduce the risk of insertional oncogenesis because they do not exhibit an integration bias toward genes and have negligible intrinsic promoter/enhancer activity [116]. Instead of adding the correct gene, the disrupted gene can also be repaired. Site-specific zinc-finger nucleases can cut out a targeted region, which is then replaced by homologous recombination with donor DNA [117]. This technology has already been used in at least three clinical trials [118].

Because of the tumor and arrhythmia risk, iPSC-derived cell therapies may be best taken to clinical trials in no-option patients who require a mechanical ventricular assist device [119]. Here, ventricular arrhythmia is usually not life threatening, and myocar- dium for histology studies can be collected upon explantation of the device or heart transplantation.

Biobanking of iPSCs from all individuals may become a standard procedure in the future. However, it remains an open question -even if we would be able to reliably differentiate iPSCs into the desired cell population- if the time needed to obtain these cells (currently a few weeks) would be compatible with the optimal time window of cell therapy treatment after an ischemic event (a few days)

\section{LESSONS FROM CLINICAL TRIALS WITH ADULT STEM CELLS OR GENE THERAPY}

Adult stem cells have been used in a number of clinical trials with varying success rates. Any in vivo applications of iPSCs and iPSC-derived cells will be scrutinized in at least as stringent fashion as these adult stem cells. Therefore, insights derived from these trials with adult stem cells may help to circumvent obstacles towards clinical translation of iPSCs.

Clinical trials with skeletal myoblasts failed to improve heart function [120], which is not surprising since skeletal myoblasts do not differentiate into cardiomyocytes and cannot electrically couple with them [121]. Many clinical trials have been initiated with bone marrow cells, but have shown only limited therapeutic benefits [122-124]. Until now there is no proof-of-concept that stem cells can substantially regenerate a damaged human heart. Exploring cardiac differentiation potential of iPSC products in preclinical and clinical settings is mandatory to avoid false expectations as well as controversies. The focus of a cellular therapy is mostly on the homing, differentiation, survival and functional integration of the transplanted cells. Given the low number of newly generated cardiomyocytes with different stem cells, the most plausible hypothesis is that the functional benefits of stem cells observed thus far are due to paracrine signaling. This is secretion of soluble factors that attenuate pathological remodeling, reduce apoptosis and induce angiogenesis. Paracrine protection should be deeply investigated in the case of iPSC-derived products used as therapeutic treatment in preclinical animal model of acute and chronic heart diseases.

When using iPSCs created through reprogramming with retroor lentiviral vectors, experience with these vectors from gene therapy trials needs to be considered. Several children with X-linked severe combined immunodeficiency treated with autologous hematopoietic stem cells modified with retroviral vectors developed leukemia. This was shown to be associated with insertion of the vector near the $L M O 2$ oncogene, thereby activating it [18]. A contributing factor was the selective in vivo advantage of the genecorrected cells. However, iPSC-derived cells transplanted to an environment in which cells are damaged may as well have a selective growth advantage over resident cells. Although the genes used for reprogramming seem to turn off after reprogramming is finished, concerns remain that the inserted genes could be reactivated or could have other subtle effects on the cell. Therefore, any genetic modification applied to iPSCs to generate them, to correct them, or to cure them, will have to be investigated for potential adverse effects.

\section{CURRENT HURDLES; DEVELOPMENTS NEEDED TO MOVE IPSCS INTO COMMERCIAL OR CLINICAL AP- PLICATIONS}

A method for cell reprogramming that is completely safe in terms of keeping the original genome intact is at the frontiers of iPSC technology development. Protein- and mRNA-based methods are currently the most promising strategies to achieve this, but are technically the more daunting ones $[27,28]$. Refinements to these methods, yielding higher efficiency may result in the generation of safer iPSCs. iPSC lines could be heterogeneous and sometimes dissimilar to human ESCs, mainly because of their relative state of reprogramming. Therefore, to avoid the use of "pseudo" iPSC lines, 
standard methods need to be developed to define their true identity as pluripotent self renewing cells. Since iPSCs from different patients may differ, the outcome of a certain process may differ. It is a matter of understanding and controlling the parameters that give rise to the variability of the cell phenotype. Defining robust processes for guided differentiation towards the cell type(s) of interest (atrial, nodal, ventricular) or reproducible mixtures of cardiomyocytes, endothelial cells, smooth muscle cells and fibroblasts will be key to all applications. Next to robust protocols, we also need assays to understand what the final product is in terms of purity, safety and potency. If there are $30 \%$ of the desired cells, then what are the other $70 \%$ of cells? Furthermore, the requirement of final maturation of cardiomyocytes is directly related to the application, i.e. less mature cardiomyocytes may be desired for regenerative strategies whereas mature cardiomyocytes are desired for drug screening.

The use of defined and xeno-free culture methods is desirable for the establishment, culture and differentiation of iPSCs. Exposure of human cells to animal-derived products increase the risk of immunoreactions and viral, bacterial or prion transmission and may limit their clinical use. Furthermore, serum-free media is desirable to eliminate variability within different serum batches. Currently, there are several xeno-free culture mediacommercially available, however not all of them support continued undifferentiated growth of ESCs, warranting further development [126,127]. In addition to PSC maintenance media, also culture conditions used for PSC differentiation will need to be based on defined xeno-free media.Also, PSCs are typically cultured on feeder cells or Matrigel, to provide an ECM-rich environment and soluble growth factors. However, this culture method has high batch-to-batch variability and limited scalability. Last year, several substrates were described that support PSC maintenance in a fully defined medium [128-131]. Furthermore, an automated and scalable culture system of human ESCs in feeder-free conditions has been described [132].

For in vivo repair, delivery methods for the cells should be carefully considered. Massive attrition occurs shortly after injection of cells into the heart, due to the limited vascular supply and the hostile environment, especially after myocardial infarction. A solution for improved cell retention that is just starting to be explored in the lab is the embedding in a hydrogel matrix, or using tissuepatches, which still face many additional hurdles [111].

The pharmaceutical industry at present has a limited interest in cell therapy products, due to their complex production processes, expected small profit margin and uncertainties regarding the intellectual property and exclusive commercial exploitation [119]. The legal situation in the European Union regarding the production and the therapeutic use of viable cells is described in the Regulation on
Advanced Therapies No 1394/2007, and the situation is comparable in North America. Cells used for tissue regeneration are considered medicinal products, hence their production and clinical application must comply with Good Manufacturing and Good Clinical Practice [119]. In general, even if the same iPSC-derivation protocol is used, each patient-specific reprogrammed cell line may be viewed as its own drug, thereby requiring its own safety tests, which might enormously increase the cost for Phase I/II clinical trials based on autologous iPSCs. Since novel stem cell-based therapies are under validation, the regulatory framework is likely to rapidly change. However, existing regulations applicable to human stem cell products provide the only available guidelines for pursuing safety and efficacy of the future generation of human iPSC-based products.

The major concern with the clinical application of iPSCs is their natural tendency to form neoplasia and teratoma, clearly evident when injected into immunodeficient mice. Teratoma formation is a major obstacle for using stem cells in regenerative medicine and iPSCs may be even more tumorigenic than ESCs [133]. In fact, all the genes that have been used to generate iPSCs have also been connected to cancer and transgenic mice derived by iPSC technology have a high probability to develop cancer. In the future, studies regarding iPSC tumorigenicity with methods that mimic the approaches potentially used in clinical trials will be crucial. An overview of the hurdles for each of the discussed applications of iPSCs is shown in (Table $\mathbf{3}$ ).

\section{CONCLUSION}

In conclusion, iPSCs and iPSC-derived cardiomyocytes recently emerged as a powerful tool to model cardiac development and congenital cardiac disorders. Although iPSC-derived cardiomyocytes do not display a fully mature phenotype, there is growing evidence supporting their usefulness in drug screening. As a model system they may also gain invaluable insights in re-activation of resident stem cells. However, many hurdles -as outlined above- still need to be overcome to bring iPSC-based products into the clinic.

\section{ACKNOWLEDGEMENTS}

This work was supported by the Nash Avery Stem Cell Research-Wicka Fund, University of Minnesota; Research Foundation - Flanders (FWO) Odysseus Program grant G.0907.08; Research Council of the University of Leuven grant OT/09/053; Cardio Repair European Multidisciplinary Initiative grant 242038 FP7-EC; the Italian Ministry of University and Scientific Research grant 2008RFNT8T_003; Cariplo grants 2007.5639 and 2008.2005; K.U.Leuven Industrial Research Fund grant HB/10/044 to MS. LT is Postdoctoral Fellow of the Research Foundation - Flanders (FWO).

Table 3. Hurdles of iPSCs as Tool for Disease Model, Drug Screening and Regenerative Medicine

\begin{tabular}{|c|c|c|c|}
\hline & Disease Model & Drug Screening & Regenerative Medicine \\
\hline iPSC generation: time, cost, genomic integrity & $\mathrm{X}$ & $\mathrm{X}$ & $\mathrm{XX}$ \\
\hline Use of defined, xeno-free media & - & $\mathrm{X}$ & $\mathrm{XXX}$ \\
\hline Teratoma formation potential & - & - & $\mathrm{XXX}$ \\
\hline Cardiomyocyte maturation & $\mathrm{XX}$ & $\mathrm{XX}$ & - \\
\hline Incorporation in $3 \mathrm{D}$ - construct & $\mathrm{X}$ & $\mathrm{XX}$ & $\mathrm{X}$ \\
\hline
\end{tabular}

XXX: hurdle which needs to be overcome, XX: hurdle, but not blocking applicability, X: issue to consider, but not necessarily needed, -: likely not an issue. 


\section{ABBREVIATIONS}

$\begin{array}{lll}2 \mathrm{D} & = & \text { Two-dimensional } \\ 3 \mathrm{D} & = & \text { Three-dimensional } \\ \mathrm{CpG} & = & \text { Cytosine-phosphate-guanine } \\ \mathrm{EB} & = & \text { Embryoid body } \\ \mathrm{ECM} & = & \text { Extracellular matrix } \\ \mathrm{ESC} & = & \text { Embryonic stem cell } \\ \text { FACS } & = & \text { Fluorescence activated cell sorting } \\ \text { hERG } & \text { Human Ether-a-go-go } \\ \text { iPSC } & \text { Induced pluripotent stem cell } \\ \text { LQTS } & = & \text { Long QT syndrome } \\ \text { PSC } & = & \text { Pluripotent stem cell (encompassing both ESC } \\ \text { QPCR } & & \text { and iPSC) }\end{array}$

\section{REFERENCES}

[1] Gurdon J, Elsdale T, Fischberg M. Sexually mature individuals of Xenopus laevis from the transplantation of single somatic nuclei. Nature 1958; 182: 64-5.

[2] Wilmut I, Schnieke AE, McWhir J, Kind AJ, Campbell KH. Viable offspring derived from fetal and adult mammalian cells. Nature 1997; 385: 810-3.

[3] Tada M, Tada T, Lefebvre L, Barton SC, Surani MA. Embryonic germ cells induce epigenetic reprogramming of somatic nucleus in hybrid cells. EMBO J 1997; 16: 6510-20.

[4] Takahashi K, Yamanaka S. Induction of pluripotent stem cells from mouse embryonic and adult fibroblast cultures by defined factors. Cell 2006; 126: 663-76.

[5] Takahashi K, Tanabe K, Ohnuki M, et al. Induction of pluripotent stem cells from adult human fibroblasts by defined factors. Cell 2007; 131: 861-72.

[6] Yu J, Vodyanik M a, Smuga-Otto K, et al. Induced pluripotent stem cell lines derived from human somatic cells. Science 2007; 318: $1917-20$

[7] Chan KK-K, Zhang J, Chia N-Y, et al. KLF4 and PBX1 directly regulate NANOG expression in human embryonic stem cells. Stem Cells 2009; 27: 2114-25.

[8] Adewumi O, Aflatoonian B, Ahrlund-Richter L, et al. Characterization of human embryonic stem cell lines by the International Stem Cell Initiative. Nat Biotechnol 2007; 25: 803-16.

[9] Vogel G. Breakthrough of the year. Reprogramming Cells. Science 2008; 322: 1766-7.

[10] Nelson TJ, Martinez-Fernandez A, Terzic A. Induced pluripotent stem cells: developmental biology to regenerative medicine. Nature Reviews Cardiology 2010; 1-11.

[11] Yamanaka S, Blau HM. Nuclear reprogramming to a pluripotent state by three approaches. Nature 2010; 465: 704-12.

[12] Nakagawa M, Koyanagi M, Tanabe K, et al. Generation of induced pluripotent stem cells without Myc from mouse and human fibroblasts. Nat Biotechnol 2008; 26: 101-6.

[13] Okita K, Ichisaka T, Yamanaka S. Generation of germlinecompetent induced pluripotent stem cells. Nature 2007; 448: 313-7.

[14] Huangfu D, Osafune K, Maehr R, et al. Induction of pluripotent stem cells from primary human fibroblasts with only Oct4 and Sox2. Nat Biotechnol 2008; 26: 1269-75.

[15] Li Y, Zhang Q, Yin X, et al. Generation of iPSCs from mouse fibroblasts with a single gene, Oct4, and small molecules. Cell Research 2010; 21: 196-204.

[16] Shao L, Feng W, Sun Y, et al. Generation of iPS cells using defined factors linked via the self-cleaving $2 \mathrm{~A}$ sequences in a single open reading frame. Cell Research 2009; 19: 296-306.

[17] Carey BW, Markoulaki S, Hanna J, et al. Reprogramming of murine and human somatic cells using a single polycistronic vector. Proc Natl Acad Sci USA 2009; 106: 157-62.

[18] Nienhuis AW, Dunbar CE, Sorrentino BP. Genotoxicity of retroviral integration in hematopoietic cells. Mol Ther 2006; 13: 1031-49.

[19] Chang C-W, Lai Y-S, Pawlik KM, et al. Polycistronic lentiviral vector for "hit and run" reprogramming of adult skin fibroblasts to induced pluripotent stem cells. Stem Cells 2009; 27: 1042-9.
[20] Stadtfeld M, Nagaya M, Utikal J, Weir G, Hochedlinger K. Induced pluripotent stem cells generated without viral integration. Science 2008; 322: 945-9.

[21] Okita K, Nakagawa M, Hyenjong H, Ichisaka T, Yamanaka S. Generation of mouse induced pluripotent stem cells without viral vectors. Science 2008; 322: 949-53

[22] Yu J, Hu K, Smuga-Otto K, et al. Human induced pluripotent stem cells free of vector and transgene sequences. Science 2009; 324 : 797-801

[23] Ye L, Chang JC, Lin C, Qi Z, Yu J, Kan YW. Generation of induced pluripotent stem cells using site-specific integration with phage integrase. Proc Natl Acad Sci USA 2010; 107: 19467-19472.

[24] Woltjen K, Michael IP, Mohseni P, et al. piggyBac transposition reprograms fibroblasts to induced pluripotent stem cells. Nature 2009; 458: 766-70

[25] Kaji K, Norrby K, Paca A, Mileikovsky M, Mohseni P, Woltjen K. Virus-free induction of pluripotency and subsequent excision of reprogramming factors. Nature 2009; 458: 771-5.

[26] Lin SL, Chang DC, Lin C-H, Ying SY, Leu D, Wu DTS. Regulation of somatic cell reprogramming through inducible mir-302 expression. Nucleic Acids Res 2011; 39: 1054

[27] Kim D, Kim C-H, Moon JI, et al. Generation of human induced pluripotent stem cells by direct delivery of reprogramming proteins. Cell Stem Cell 2009; 4: 472-6.

[28] Warren L, Manos PD, Ahfeldt T, et al. Highly Efficient Reprogramming to Pluripotency and Directed Differentiation of Human Cells with Synthetic Modified mRNA. Cell Stem Cell 2010; 1-13.

[29] Seki T, Yuasa S, Oda M, et al. Generation of induced pluripotent stem cells from human terminally differentiated circulating $\mathrm{T}$ cells Cell Stem Cell 2010; 7: 11-4.

[30] Fusaki N, Ban H, Nishiyama A, Saeki K, Hasegawa M. Efficient induction of transgene-free human pluripotent stem cells using a vector based on Sendai virus, an RNA virus that does not integrate into the host genome. Proc Jpn Acad, Ser B 2009; 85: 348-362.

[31] Aasen T, Raya A, Barrero MJ, et al. Efficient and rapid generation of induced pluripotent stem cells from human keratinocytes. Nat Biotechnol 2008; 26: 1276-84.

[32] Loh Y-H, Hartung O, Li H, et al. Reprogramming of T cells from human peripheral blood. Cell Stem Cell 2010; 7: 15-9.

[33] Staerk J, Dawlaty MM, Gao Q, et al. Reprogramming of Human Peripheral Blood Cells to Induced Pluripotent Stem Cells. Cell Stem Cell 2010; 7: 20-24.

[34] Brown ME, Rondon E, Rajesh D, et al. Derivation of induced pluripotent stem cells from human peripheral blood $\mathrm{T}$ lymphocytes. PloS One 2010; 5: e11373.

[35] Eminli S, Foudi A, Stadtfeld M, et al. Differentiation stage determines potential of hematopoietic cells for reprogramming into induced pluripotent stem cells. Nat Genet 2009; 41: 968-76.

[36] Bunnell BA, Flaat M, Gagliardi C, Patel B, Ripoll C. Adiposederived stem cells: isolation, expansion and differentiation. Methods 2008; 45: 115-20.

[37] Sun N, Panetta NJ, Gupta DM, et al. Feeder-free derivation of induced pluripotent stem cells from adult human adipose stem cells. Proc Natl Acad Sci USA 2009; 106: 15720-5.

[38] Bobbert M. Ethical questions concerning research on human embryos, embryonic stem cells and chimeras. Biotechnol J 2006; 1 : 1352-69.

[39] Marchetto MCN, Yeo GW, Kainohana O, Marsala M, Gage FH, Muotri AR. Transcriptional signature and memory retention of human-induced pluripotent stem cells. PloS One 2009; 4: e7076.

[40] Chin MH, Mason MJ, Xie W, et al. Induced pluripotent stem cells and embryonic stem cells are distinguished by gene expression signatures. Cell Stem Cell 2009; 5: 111-23

[41] Wang Y, Mah N, Prigione A, Wolfrum K, Andrade-Navarro MA Adjaye J. A Transcriptional Roadmap to the Induction of Pluripotency in Somatic Cells. Stem Cell Reviews 2010; 6: 282-96.

[42] Malchenko S, Galat V, Seftor EA, et al. Cancer hallmarks in induced pluripotent cells: New insights. J Cell Physiol 2010; 225: 390-3.

[43] Kim K, Doi A, Wen B, et al. Epigenetic memory in induced pluripotent stem cells. Nature 2010; 467: 285-90.

[44] Polo JM, Liu S, Figueroa ME, et al. Cell type of origin influences the molecular and functional properties of mouse induced pluripotent stem cells. Nat Biotechnol 2010; 28: 848-855. 
[45] Quattrocelli M, Palazzolo G, Floris G, et al. Intrinsic cell memory reinforces myogenic commitment of pericyte-derived iPSCs. J Pathology 2011; 223: 593-603.

[46] Lister R, Pelizzola M, Kida YS, et al. Hotspots of aberrant epigenomic reprogramming in human induced pluripotent stem cells. Nature 2011; 471: 68-73.

[47] Hussein SM, Batada NN, Vuoristo S, et al. Copy number variation and selection during reprogramming to pluripotency. Nature 2011; 471: 58-62.

[48] Stadtfeld M, Apostolou E, Akutsu H, et al. Aberrant silencing of imprinted genes on chromosome $12 \mathrm{qF} 1$ in mouse induced pluripotent stem cells. Nature 2010; 465: 175-81.

[49] Newman AM, Cooper JB. Lab-Specific Gene Expression Signatures in Pluripotent Stem Cells. Cell Stem Cell 2010; 7: 258-262.

[50] Mayshar Y, Ben-David U, Lavon N, et al. Identification and classification of chromosomal aberrations in human induced pluripotent stem cells. Cell Stem Cell 2010; 7: 521-31.

[51] Laurent LC, Ulitsky I, Slavin I, et al. Dynamic Changes in the Copy Number of Pluripotency and Cell Proliferation Genes in $\mathrm{Hu}-$ man ESCs and iPSCs during Reprogramming and Time in Culture. Cell Stem Cell 2011; 8: 106-18.

[52] Gore A, Li Z, Fung H-lim, et al. Somatic coding mutations in human induced pluripotent stem cells. Nature 2011; 470: 63-67.

[53] Vanneste E, Voet T, Le Caignec C, et al. Chromosome instability is common in human cleavage-stage embryos. Nature Medicine 2009; 15: 577-83.

[54] Doi A, Park I-H, Wen B, et al. Differential methylation of tissueand cancer-specific $\mathrm{CpG}$ island shores distinguishes human induced pluripotent stem cells, embryonic stem cells and fibroblasts. Nat Genet 2009; 41: 1350-3.

[55] Pera MF. Stem cells: The dark side of induced pluripotency. Nature 2011; 471: 46-47.

[56] Gupta MK, Illich DJ, Gaarz A, et al. Global transcriptional profiles of beating clusters derived from human induced pluripotent stem cells and embryonic stem cells are highly similar. BMC Developmental Biology 2010; 10: 98.

[57] Narsinh KH, Sun N, Sanchez-Freire V, Lee AS, Almeida P, Hu S, et al. Single cell transcriptional profiling reveals heterogeneity of human induced pluripotent stem cells. J Clin Invest 2011; 121: 1217-21.

[58] Vidarsson H, Hyllner J, Sartipy P. Differentiation of human embryonic stem cells to cardiomyocytes for in vitro and in vivo applications. Stem Cell Reviews 2010; 6: 108-20.

[59] Kehat I, Kenyagin-Karsenti D, et al. Human embryonic stem cells can differentiate into myocytes with structural and functional properties of cardiomyocytes. J Clin Invest 2001; 108: 407-14.

[60] Zhang J, Wilson GF, Soerens AG, et al. Functional cardiomyocytes derived from human induced pluripotent stem cells. Circ Res 2009; 104: e30-41.

[61] Yoon BS, Yoo SJ, Lee JE, You S, Lee HT, Yoon HS. Enhanced differentiation of human embryonic stem cells into cardiomyocytes by combining hanging drop culture and 5-azacytidine treatment. Differentiation 2006; 74: 149-59.

[62] Ng ES, Davis RP, Azzola L, Stanley EG, Elefanty AG. Forced aggregation of defined numbers of human embryonic stem cells into embryoid bodies fosters robust, reproducible hematopoietic differentiation. Blood 2005; 106: 1601-3.

[63] Niebruegge S, Bauwens CL, Peerani R, et al. Generation of human embryonic stem cell-derived mesoderm and cardiac cells using size-specified aggregates in an oxygen-controlled bioreactor. Biotechnol Bioeng 2009; 102: 493-507.

[64] Mummery C, Ward-van Oostwaard D, Doevendans P, et al. Differentiation of human embryonic stem cells to cardiomyocytes: role of coculture with visceral endoderm-like cells. Circulation 2003; 107: 2733-40.

[65] Passier R, Oostwaard DW-van, Snapper J, et al. Increased cardiomyocyte differentiation from human embryonic stem cells in serum-free cultures. Stem Cells 2005; 23: 772-80.

[66] Graichen R, Xu X, Braam SR, et al. Enhanced cardiomyogenesis of human embryonic stem cells by a small molecular inhibitor of p38 MAPK. Differentiation 2008; 76: 357-70.

[67] Yan P, Nagasawa A, Uosaki H, et al. Cyclosporin-A potently induces highly cardiogenic progenitors from embryonic stem cells. Biochem Biophys Res Commun 2009; 379: 115-20.

[68] Fujiwara M, Yan P, Otsuji TG, et al. Induction and Enhancement of Cardiac Cell Differentiation from Mouse and Human Induced
Pluripotent Stem Cells with Cyclosporin-A. PloS One 2011; 6: e16734.

[69] Xu XQ, Graichen R, Soo SY, et al. Chemically defined medium supporting cardiomyocyte differentiation of human embryonic stem cells. Differentiation 2008; 76: 958-70.

[70] Laflamme M a, Chen KY, Naumova AV, et al. Cardiomyocytes derived from human embryonic stem cells in pro-survival factors enhance function of infarcted rat hearts. Nat Biotechnol 2007; 25: 1015-24.

[71] Yang L, Soonpaa MH, Adler ED, et al. Human cardiovascular progenitor cells develop from a KDR+ embryonic-stem-cellderived population. Nature 2008; 453: 524-8.

[72] Gadue P, Huber TL, Paddison PJ, Keller GM. Wnt and TGF-beta signaling are required for the induction of an in vitro model of primitive streak formation using embryonic stem cells. Proc Natl Acad Sci USA 2006; 103: 16806-11.

[73] Tran TH, Wang X, Browne C, et al. Wnt3a-induced mesoderm formation and cardiomyogenesis in human embryonic stem cells. Stem Cells 2009; 27: 1869-78.

[74] Blin G, Nury D, Stefanovic S, et al. A purified population of multipotent cardiovascular progenitors derived from primate pluripotent stem cells engrafts in postmyocardial infarcted nonhuman primates. J Clin Invest 2010; 120: 1125-39.

[75] Willems E, Bushway PJ, Mercola M. Natural and synthetic regulators of embryonic stem cell cardiogenesis. Pediatric Cardiology 2009; 30: 635-42.

[76] Small EM, Olson EN.Pervasive roles of microRNAs in cardiovascular biology. Nature 2011; 469: 336-342.

[77] Hattori F, Chen H, Yamashita H, et al. Nongenetic method for purifying stem cell-derived cardiomyocytes. Nat Methods 2010; 7: 61-6.

[78] Efe JA, Hilcove S, Kim J, et al. Conversion of mouse fibroblasts into cardiomyocytes using a direct reprogramming strategy. Nat Cell Biol 2011; 13: 215-222.

[79] Ieda M, Fu J-D, Delgado-Olguin P, et al. Direct Reprogramming of Fibroblasts into Functional Cardiomyocytes by Defined Factors. Cell 2010; 142: 375-86.

[80] Kattman SJ, Witty AD, Gagliardi M, et al. Stage-Specific Optimization of Activin/Nodal and BMP Signaling Promotes Cardiac Differentiation of Mouse and Human Pluripotent Stem Cell Lines. Cell Stem Cell 2011; 8: 228-40.

[81] Schlesinger J, Schueler M, Grunert M, et al. The Cardiac Transcription Network Modulated by Gata4, Mef2a, Nkx2.5, Srf, Histone Modifications, and MicroRNAs. PLoS Genet 2011; 7: e1001313.

[82] Sturzu a C, Wu SM. Developmental and Regenerative Biology of Multipotent Cardiovascular Progenitor Cells. Circ Res 2011; 108: 353-64.

[83] Itzhaki I, Maizels L, Huber I, et al. Modelling the long QT syndrome with induced pluripotent stem cells. Nature 2011; 471: 2259.

[84] Moretti A, Bellin M, Welling A, et al. Patient-Specific Induced Pluripotent Stem-Cell Models for Long-QT Syndrome. N Engl J Med 2010; 1-13.

[85] Yazawa M, Hsueh B, Jia X, et al. Using induced pluripotent stem cells to investigate cardiac phenotypes in Timothy syndrome. Nature 2011; 471: 230-4.

[86] Kamp TJ. An Electrifying iPSC Disease Model: Long QT Syndrome Type 2 and Heart Cells in a Dish. Cell Stem Cell 2011; 8: 130-1.

[87] Carvajal-Vergara X, Sevilla A, D'Souza SL, et al. Patient-specific induced pluripotent stem-cell-derived models of LEOPARD syndrome. Nature 2010; 465: 808-12.

[88] Yoshida Y, Yamanaka S. Recent stem cell advances: induced pluripotent stem cells for disease modeling and stem cell-based regeneration. Circulation 2010; 122: 80-7.

[89] Kola I, Landis J. Can the pharmaceutical industry reduce attrition rates? Nat Rev Drug Discovery 2004; 3: 711-5.

[90] Callaway E. Cells snag top modelling job. Nature 2011; 469: 279.

[91] Sartiani L, Bettiol E, Stillitano F, Mugelli A, Cerbai E, Jaconi ME. Developmental changes in cardiomyocytes differentiated from human embryonic stem cells: a molecular and electrophysiological approach. Stem Cells 2007; 25: 1136-44.

[92] Cavero I, Crumb W. ICH S7B draft guideline on the non-clinical strategy for testing delayed cardiac repolarisation risk of drugs: a critical analysis. Expert opinion on drug safety 2005; 4: 509-30. 
[93] Tanaka T, Tohyama S, Murata M, et al. In vitro pharmacologic testing using human induced pluripotent stem cell-derived cardiomyocytes. Biochem Biophys Res Commun 2009; 385: 497-502.

[94] Braam SR, Tertoolen L, Stolpe A van de, Meyer T, Passier R, Mummery CL. Prediction of drug-induced cardiotoxicity using human embryonic stem cell-derived cardiomyocytes. Stem Cell Research 2010; 4: 107-16.

[95] Gai H, Leung EL-H, Costantino PD, et al. Generation and characterization of functional cardiomyocytes using induced pluripotent stem cells derived from human fibroblasts. Cell Biology International 2009; 33: 1184-93.

[96] Otsuji TG, Minami I, Kurose Y, Yamauchi K, Tada M, Nakatsuji $\mathrm{N}$. Progressive maturation in contracting cardiomyocytes derived from human embryonic stem cells: Qualitative effects on electrophysiological responses to drugs. Stem Cell Research 2010; 4: 20113.

[97] Kim C, Majdi M, Xia P, et al. Non-cardiomyocytes influence the electrophysiological maturation of human embryonic stem cellderived cardiomyocytes during differentiation. Stem Cells and Development 2010; 19: 783-95.

[98] Hansen A, Eder A, Bönstrup M, et al. Development of a Drug Screening Platform Based on Engineered Heart Tissue. Circ Res 2010 ;

[99] Vandenburgh H, Shansky J, Benesch-Lee F, et al. Drug-screening platform based on the contractility of tissue-engineered muscle. Muscle Nerve 2008; 37: 438-47.

[100] Salameh A, Wustmann A, Karl S, et al. Cyclic mechanical stretch induces cardiomyocyte orientation and polarization of the gap junction protein connexin43. Circ Res 2010; 106: 1592-602.

[101] Porrello ER, Mahmoud a I, Simpson E, et al. Transient Regenerative Potential of the Neonatal Mouse Heart. Science 2011; 331: 1078-1080.

[102] Nelson TJ, Martinez-Fernandez A, Yamada S, Perez-Terzic C, Ikeda Y, Terzic A. Repair of acute myocardial infarction by human stemness factors induced pluripotent stem cells. Circulation 2009; 120: 408-16.

[103] Ahmed RP, Ashraf M, Buccini S, Shujia J, Haider HK. Cardiac tumorgenic potential of induced pluripotent stem cells in an immunocompetent host with myocardial infarction. Regenerative Medicine 2011; 6: 171-8.

[104] Moretti A, Bellin M, Jung CB, et al. Mouse and human induced pluripotent stem cells as a source for multipotent Is11+ cardiovascular progenitors. FASEB J 2010; 24: 700-11

[105] Yoon C-H, Koyanagi M, Iekushi K, et al. Mechanism of improved cardiac function after bone marrow mononuclear cell therapy: role of cardiovascular lineage commitment. Circulation 2010; 121: 2001-11

[106] Banerjee I, Fuseler JW, Price RL, Borg TK, Baudino T a. Determination of cell types and numbers during cardiac development in the neonatal and adult rat and mouse. Am J Physiol 2007; 293: H188391

[107] Snider P, Standley KN, Wang J, Azhar M, Doetschman T, Conway SJ.Origin of cardiac fibroblasts and the role of periostin. Circ Res 2009; 105: 934-47.

[108] Noseda M, Schneider MD. Fibroblasts inform the heart: control of cardiomyocyte cycling and size by age-dependent paracrine signals. Dev Cell 2009; 16: 161-2.

[109] Kamkin A, Kiseleva I, Lozinsky I, Scholz H. Electrical interaction of mechanosensitive fibroblasts and myocytes in the heart. Basic Research in Cardiology 2005; 100: 337-45.

[110] Thorrez L, Shansky J, Wang L, et al. Growth, differentiation, transplantation and survival of human skeletal myofibers on biodegradable scaffolds. Biomaterials 2008; 29: 75-84.

[111] Vunjak-Novakovic G, Tandon N, Godier A, et al. Challenges in cardiac tissue engineering. Tissue Engineering. Part B, Reviews 2010; 16: 169-87.

[112] Thorrez L, Vandenburgh H, Callewaert N, et al. Angiogenesis enhances factor IX delivery and persistence from retrievable human bioengineered muscle implants. Mol Ther 2006; 14: 442-51.

[113] Stevens KR, Kreutziger KL, Dupras SK, et al. Physiological function and transplantation of scaffold-free and vascularized human cardiac muscle tissue. Proc Natl Acad Sci USA 2009; 106: 1656873.

[114] Suzuki H, Shibata R, Kito T, et al. Therapeutic angiogenesis by transplantation of induced pluripotent stem cell-derived Flk-1 positive cells. BMC Cell Biology 2010; 11: 72.

[115] Kleger A, Seufferlein T, Malan D, et al. Modulation of calciumactivated potassium channels induces cardiogenesis of pluripotent stem cells and enrichment of pacemaker-like cells. Circulation 2010; 122: 1823-36.

[116] Belay E, Mátrai J, Acosta-Sanchez A, et al. Novel Hyperactive Transposons for Genetic Modification of Induced Puripotent and Adult Stem Cells: A Non-Viral Paradigm for Coaxed Differentiation. Stem Cells 2010; 1760-71.

[117] Hockemeyer D, Soldner F, Beard C, et al. Efficient targeting of expressed and silent genes in human ESCs and iPSCs using zincfinger nucleases. Nat Biotechnol 2009; 27: 851-7.

[118] Urnov FD, Rebar EJ, Holmes MC, Zhang HS, Gregory PD. Genome editing with engineered zinc finger nucleases. Nat Rev Genet 2010; 11: 636-46.

[119] Choi Y-H, Saric T, Nasseri B, et al. Cardiac Cell Therapies: The Next Generation. Cardiovascular Therapeutics 2010; 29: 2-16.

[120] Menasché P, Alfieri O, Janssens S, et al. The Myoblast Autologous Grafting in Ischemic Cardiomyopathy (MAGIC) trial: first randomized placebo-controlled study of myoblast transplantation. Circulation 2008; 117: 1189-200.

[121] Leobon B, Garcin I, Menasche P, Vilquin J-T, Audinat E, Charpak S. Myoblasts transplanted into rat infarcted myocardium are functionally isolated from their host. Proc Natl Acad Sci USA 2003; 100: 7808-11.

[122] Hendrikx M, Hensen K, Clijsters C, et al. Recovery of regional but not global contractile function by the direct intramyocardial autologous bone marrow transplantation: results from a randomized controlled clinical trial. Circulation 2006; 114: I101-7.

[123] Janssens S, Dubois C, Bogaert J, et al. Autologous bone marrowderived stem-cell transfer in patients with ST-segment elevation myocardial infarction: double-blind, randomised controlled trial. Lancet 2006; 367: 113-21.

[124] Meyer GP, Wollert KC, Lotz J, et al. Intracoronary bone marrow cell transfer after myocardial infarction: eighteen months' followup data from the randomized, controlled BOOST (BOne marrOw transfer to enhance ST-elevation infarct regeneration) trial. Circulation 2006; 113: 1287-94

[125] Joggerst SJ, Hatzopoulos AK. Stem cell therapy for cardiac repair: benefits and barriers. Expert Rev Mol Med 2009; 11: e20.

[126] Rajala K, Lindroos B, Hussein SM, et al. A defined and xeno-free culture method enabling the establishment of clinical-grade human embryonic, induced pluripotent and adipose stem cells. PloS One 2010; 5: e10246.

[127] Rajala K, Hakala H, Panula S, et al. Testing of nine different xenofree culture media for human embryonic stem cell cultures. Hum Reprod 2007; 22: 1231-8.

[128] Melkoumian Z, Weber JL, Weber DM, et al. Synthetic peptideacrylate surfaces for long-term self-renewal and cardiomyocyte differentiation of human embryonic stem cells. Nat Biotechnol 2010 28: 606-610.

[129] Villa-Diaz LG, Nandivada H, Ding J, et al. Synthetic polymer coatings for long-term growth of human embryonic stem cells. Nat Biotechnol 2010; 28: 581-583.

[130] Rodin S, Domogatskaya A, Ström S, et al. Long-term self-renewal of human pluripotent stem cells on human recombinant laminin511. Nat Biotechnol 2010; 28: 611-5.

[131] Klim JR, Li L, Wrighton PJ, Piekarczyk MS, Kiessling LL. A defined glycosaminoglycan-binding substratum for human pluripotent stem cells. Nat Methods 2010; 7: 989-94.

[132] Thomas RJ, Anderson D, Chandra A, et al. Automated, scalable culture of human embryonic stem cells in feeder-free conditions. Biotechnol Bioeng 2009; 102: 1636-44.

[133] Gutierrez-Aranda I, Ramos-Mejía V, Bueno C, et al. Human Induced Pluripotent Stem Cells Develop Teratoma More Efficiently and Faster than Human Embryonic Stem Cells Regardless the Site of Injection. Stem Cells 2010; 28: 1568-70. 